\title{
Treatment of familial hypercholesterolaemia. United Kingdom lipid clinics study of pravastatin and cholestyramine
}

\author{
D J Betteridge, D Bhatnager, R F Bing, P N Durrington, G R Evans, H Flax, R H Jay, \\ N Lewis-Barned, J Mann, D R Matthews, J P Miller, J P D Reckless, R Sturley, K G Taylor, \\ A F Winder
}

University College and Middlesex School of Medicine, Middlesex Hospital, London WIN 8AA

D J Betteridge, reader in medicine

R H Jay, honorary lecturer

Manchester Royal Infirmary

D Bhatnager, lecturer in clinical biochemistry and metabolic medicine

P N Durrington, senior

lecturer in medicine

Glenfield General Hospital, Leicester R F Bing, senior lecturer in medicine

Dudley Road Hospital, Birmingham

G R Evans, research registrar

K G Taylor, consultant

physician

Diabetes Research Laboratory, Radcliffe Infirmary, Oxford

H Flax, research registrar D R Matthews, honorary consultant physician

John Radcliffe Hospital, Oxford

$\mathrm{N}$ Lewis-Barned, research fellow

J Mann, honorary consultant physician

University Hospital of South Manchester

J P Miller, consultant physician

Royal United Hospital, Bath

J P D Reckless, consultant physician

R Sturley, research fellow

Royal Free NHS Trust and School of Medicine, London

A F Winder, professor of chemical pathology

Correspondence to: Dr Betteridge, department of medicine.

\section{Abstract}

Objective-To compare the efficacy and safety of cholestyramine, an anion exchange resin, and pravastatin, a new hydrophilic specific inhibitor of 3-hydroxy-3-methylglutaryl coenzyme A reductase, in the treatment of heterozygous familial hypercholesterolaemia.

Design-Double blind, double dummy, placebo controlled study with three parallel groups.

Setting-Six specialist lipid clinics in the United Kingdom.

Patients - 128 patients aged 18-70 with heterozygous familial hypercholesterolaemia diagnosed on strict biochemical and clinical findings.

Main outcome measures-Total plasma cholesterol, triglyceride, and lipoprotein subfractions and biochemical and haematological safety parameters.

Results-Pravastatin $(40 \mathrm{mg} /$ day) led to a $25 \%$ reduction in total plasma cholesterol concentration and a reduction in low density lipoprotein cholesterol concentration of $30 \%$. Cholestyramine (24 $\mathrm{g} /$ day) led to similar reductions in concentrations of total cholesterol $(23 \%)$ and low density lipoprotein cholesterol (31\%). No consistent changes occurred in high density lipoprotein cholesterol values with either compound. Plasma triglyceride concentrations showed a small rise $(18 \%)$ on resin therapy. No serious adverse drug reactions occurred during the study.

Conclusions-Pravastatin seems to be a highly effective, well tolerated drug for severe hypercholesterolaemia. Patients chosen for this study were recruited on the basis that they could tolerate a full dose of cholestyramine, and in this situation cholestyramine was also highly effective in lowering plasma low density lipoprotein cholesterol concentrations.

\section{Introduction}

Increasing evidence points to a causal role for low density lipoprotein in atherosclerosis related disease, particularly coronary heart disease. ${ }^{2}$ Primary prevention trials of cholesterol lowering drugs in high risk, middle aged men have provided strong evidence of benefit in terms of reduced incidence of coronary heart disease..$^{3-5}$ In addition, recent coronary angiographic studies have shown that lipid lowering therapy has a significant impact on atheroma plaque development, progression, and regression. ${ }^{6-8}$

People with familial hypercholesterolaemia have a particularly high risk of coronary heart disease. This autosomal dominant disorder is characterised clinically by hypercholesterolaemia, tendon xanthomas, and the development of premature coronary heart disease; over half of male heterozygotes and $15 \%$ of women die before the age of $60 .^{9}$ The genetic abnormality has been well described by Brown and Goldstein and colleagues and consists of decreased low density lipoprotein cholesterol catabolism due to absent or defective cell membrane low density lipoprotein receptors. As a consequence the plasma residence time of the lipoprotein is prolonged and the plasma concentration of low density lipoprotein cholesterol is doubled in heterozygotes and quadrupled in homozygotes with this condition. ${ }^{10}$

Heterozygous familial hypercholesterolaemia affects roughly one in 500 of the United Kingdom population. Plasma cholesterol concentrations show little response to dietary measures, and hypolipidaemic drug therapy is almost invariably indicated in these patients. ${ }^{91}$ Often more than one drug is required for satisfactory reduction of plasma cholesterol concentrations. ${ }^{912}$

The introduction of specific competitive inhibitors of 3-hydroxy-3-methylglutaryl coenzyme A reductase into clinical practice represents a major advance in therapy for reducing plasma low density lipoprotein cholesterol concentrations. ${ }^{13}$ We have compared the safety and efficacy of pravastatin and cholestyramine in 128 patients heterozygous for familial hypercholesterolaemia. Pravastatin is a hydrophilic, specific in hibitor of 3-hydroxy-3-methylglutaryl coenzyme A reductase, the main rate determining enzyme in cholesterol biosynthesis. ${ }^{14}$ Cholestyramine is an anion exchange resin which binds bile salts and is widely used as a first line treatment for hypercholesterolaemia. ${ }^{12}$

\section{Subjects and methods}

One hundred and twenty eight patients with heterozygous familial hypercholesterolaemia were entered into the study. Patients were recruited from six specialist lipid clinics in London, Oxford, Manchester, Birmingham, Leicester, and Bath. The study was performed during 1988 to 1991.

Familial hypercholesterolaemia was defined as a total plasma cholesterol concentration $\geqslant 7.5 \mathrm{mmol} / \mathrm{l}$, low density lipoprotein cholesterol concentration $\geqslant 5.0 \mathrm{mmol} / \mathrm{l}$, and tendon xanthomas present in the patient or a first degree relative. Patients were also entered into the study if, in addition to raised total plasma and low density lipoprotein cholesterol concentrations, they had a parent who had died prematurely of myocardial infarction - that is, a father who had died below the age of 50 or a mother who had died below the age of 60 .

All patients were known to be tolerant of a minimum of four and preferably six sachets of cholestyramine daily before entry. Participants were men and postmenopausal or surgically sterile women aged $18-70$ who had no other primary or secondary causes of hyperlipidaemia and no significant renal, hepatic, or 
endocrine (except stable thyroid replacement) disease. Patients with hypertension (blood pressure $\geqslant 160 \mathrm{~mm} \mathrm{Hg}$ systolic or $\geqslant 100 \mathrm{~mm} \mathrm{Hg}$ diastolic), poorly controlled cardiac failure, obesity $(\geqslant 130 \%$ of ideal body weight), recent myocardial infarction (within three months), unstable angina, and excess alcohol intake ( $>5$ units/day) were excluded, as were patients with medical conditions (other than coronary heart disease) likely to limit life span to less than five years.

Patients receiving corticosteroids, oestrogens, androgens, lipid lowering agents, anticoagulants, theophylline, barbiturates, or regular aluminium containing antacids were excluded unless these agents could be withdrawn at least eight weeks before randomisation.

\section{TRIAL DESIGN}

Before entry to the study patients had any lipid lowering agents withdrawn for four weeks (bile sequestrant resins), 12 weeks (probucol), or eight weeks (all other agents). All patients were of stable weight and had been taking an established low fat, low cholesterol lipid lowering diet for at least three months before randomisation. Patients were instructed in the principles of diet in accordance with recommendations of the European Atherosclerosis Society" and American Heart Association.'

Checks on dietary compliance by professional dietitians with four day food record were undertaken before entry to the study and at 12 and 24 weeks. All patients had a dietary lead in period of six weeks before randomisation. Randomisation was stratified by centre and treatment units assigned consecutively to obtain equal numbers of patients in the three treatment groups.

The study was double blind, double dummy, and placebo controlled with the following three paralle groups: (1) pravastatin $20 \mathrm{mg}$ twice daily and cholestyramine placebo, (2) cholestyramine $16-24 \mathrm{~g}$ daily in divided doses and pravastatin placebo, and (3) pravastatin placebo and cholestyramine placebo.

The primary focus of the study was comparison of the two treatment groups with the placebo group at 12 weeks. However, to obtain more long term data groups 1 and 2 were continued on treatment for 24 weeks. In addition, group 3 receiving double placebo were rerandomised to receive active treatment with pravastatin or cholestyramine with appropriate placebo for a further 12 weeks

Cholestyramine (16-24 g) was taken well diluted with fluid before meals in two or three divided doses

TABLE I-Baseline mean (SEM) lipid and lipoprotein concentrations in three study groups

\begin{tabular}{|c|c|c|c|c|c|c|}
\hline & $\begin{array}{l}\text { No of men/ } \\
\text { No of women }\end{array}$ & $\begin{array}{c}\text { Total } \\
\text { cholesterol } \\
(\mathrm{mmol} / \mathrm{l})\end{array}$ & $\begin{array}{c}\text { Total } \\
\text { triglyceride } \\
(\mathrm{mmol} / \mathrm{l})\end{array}$ & $\begin{array}{c}\text { Low density } \\
\text { lipoprotein } \\
\text { cholesterol } \\
(\mathrm{mmol} / \mathrm{l})\end{array}$ & $\begin{array}{l}\text { High density } \\
\text { lipoprotein } \\
\text { cholesterol } \\
(\mathrm{mmol} / \mathrm{l})\end{array}$ & $\begin{array}{c}\text { Low density } \\
\text { lipoprotein } \\
\text { cholesterol: } \\
\text { high density } \\
\text { lipoprotein } \\
\text { cholesterol } \\
\text { ratio }\end{array}$ \\
\hline Placebo & $31 / 12$ & $9 \cdot 48(1 \cdot 26)$ & $1.55(0.12)$ & $7 \cdot 47(0 \cdot 26)$ & $1 \cdot 13(0.04)$ & $6.59(0.37)$ \\
\hline Pravastatin & $31 / 12$ & $9 \cdot 87(1 \cdot 26)$ & $1.52(0.10)$ & $7 \cdot 82(0 \cdot 29)$ & $1 \cdot 17(0.05)$ & $6.63(0.40)$ \\
\hline Cholestyramine & $30 / 12$ & $9 \cdot 51(1 \cdot 23)$ & $1.42(0.12)$ & $7 \cdot 63(0 \cdot 23)$ & $1.08(0.04)$ & $7.07(0.36)$ \\
\hline
\end{tabular}

TABLE II - Lipid and lipoprotein concentrations in subjects with familial hypercholesterolaemia treated with placebo, pravastatin, or cholestyramine for 12 weeks

\begin{tabular}{|c|c|c|c|c|}
\hline \multirow[b]{2}{*}{ Variable } & \multirow{2}{*}{$\begin{array}{l}\text { Pooled mean } \\
\text { at baseline }\end{array}$} & \multicolumn{3}{|c|}{ Percentage change from baseline ( $95 \%$ confidence interval) } \\
\hline & & Placebo & Pravastatin & Cholestyramine \\
\hline Total cholesterol & $9.62 \mathrm{mmol} / \mathrm{l}$ & $-2(-7$ to 4$)$ & $-25(-29$ to -21$)$ & $-23(-28$ to -19$)$ \\
\hline Total triglyceride & $1.50 \mathrm{mmol} / \mathrm{l}$ & $2(-13$ to 15$)$ & $-14(-24$ to -2$)$ & $18(3$ to 36$)$ \\
\hline Low density lipoprotein cholesterol & $7.64 \mathrm{mmol} / \mathrm{l}$ & $-2(-9$ to 4$)$ & $-30(-35$ to -25$)$ & $-31(-36$ to -26$)$ \\
\hline High density lipoprotein cholesterol & $1.13 \mathrm{mmol} / 1$ & $-6(-14$ to 3$)$ & $0(-9$ to 10$)$ & $4(-6$ to 15$)$ \\
\hline $\begin{array}{l}\text { Low density lipoprotein cholesterol: high } \\
\text { density lipoprotein cholesterol ratio }\end{array}$ & 6.76 & $4(-9$ to 18$)$ & $-30(-38$ to -20$)$ & $-34(-43$ to -25$)$ \\
\hline
\end{tabular}

and built up to full dose over two weeks from week zero. Pravastatin or its placebo was taken before morning and evening meals, at least one hour before cholestyramine. Morning drug dosages were delayed on visit days until after blood sampling.

\section{MEASUREMENTS AND ETHICS}

A full clinical history and physical examination were performed before entry and at 12 and 24 weeks. Intercurrent illnesses, possible use of non-study drugs, and any adverse effects were monitored at 2, 4, 8, 14, 16, 20, and 24 weeks. Full ophthalmological assessment with slit lamp examination and slit lamp camera photography using a detailed standard protocol was carried out before initial randomisation and at 24 weeks. A chest $x$ ray picture and an electrocardiogram were obtained before randomisation and electrocardiography repeated at 12 and 24 weeks.

Plasma total cholesterol, plasma total triglyceride, and high density lipoprotein cholesterol concentrations were measured and low density lipoprotein cholesterol value calculated before dietary lead in (minus six weeks), two weeks before randomisation, and at 2, 4, 8, $12,14,16,20$, and 24 weeks in venous samples taken from recumbent patients after a 14 hour fast. Lipid values were measured by standard enzymatic colorimetric techniques using the cholesterol oxidase/ peroxidase-amidopyrine method for cholesterol and glycerinphosphatoxidase peroxidase-amidopyrine method for triglycerides (Boehringer Mannheim, Lewes, Sussex). High density lipoprotein cholesterol was measured after precipitation of apoprotein B containing lipoproteins with heparin and manganese. ${ }^{16}$ Low density lipoprotein cholesterol values were calculated by using the Friedewald formula. ${ }^{17}$

Haematological and biochemical safety parameters were assessed before dietary lead in, two weeks before randomisation, and at $2,4,8,12,14,16,20$, and 24 weeks. Haematological measurements included full blood count, platelet count, activated partial thromboplastin time, and prothrombin time. Biochemical measurements included plasma urea, electrolyte, creatinine, glucose, urate, calcium, bilirubin, albumin, globulin, alkaline phosphatase, alanine aminotransferase, aspartate aminotransferase, $\gamma$-glutamyltransferase, and creatine kinase values.

The protocol was approved by the ethics committee at each participating institution. The nature and purpose of the study were explained in detail to each patient, each patient was given an information sheet, and written informed consent was obtained. The patients' general practitioners were informed before study commencement.

\section{STATISTICS}

Lipid and lipoprotein values are presented as means and standard error. Analysis of covariance was used to compare the treatment groups with respect to changes in lipid and lipoprotein concentrations from baseline values. Log transformation of raw data was performed before analysis. Data on patients withdrawn from the study $(n=10)$ are included in the analysis up to the point of withdrawal. Statistical analysis was confined to the 12 week placebo controlled study period.

\section{Results}

Baseline characteristics of the hypercholesterolaemic subjects studied are shown in table I. Lipid and lipoprotein concentrations were similar in the three groups.

The 12 week comparison of the pravastatin, cholestyramine, and placebo treated groups are shown in table II. Similar reductions were observed in total cholesterol concentration, low density lipoprotein 
cholesterol concentration, and ratio of low density lipoprotein cholesterol to high density lipoprotein cholesterol in the two active treatment groups compared with the placebo group $(\mathrm{p}<0.001)$. Pravastatin was associated with a $25 \%$ fall in plasma cholesterol concentration at 12 weeks. A significant fall in plasma cholesterol value was seen at two weeks and was maximal at four weeks. The reduction in total plasma cholesterol concentration was explained by a reduction in low density lipoprotein cholesterol of $30 \%$. There was no change in the concentration of high density lipoprotein cholesterol, but a highly significant reduction in the ratio of low density lipoprotein cholesterol to high density lipoprotein cholesterol was observed $(\mathrm{p}<0.001)$. Plasma triglyceride concentration fell by $14 \%$; this reduction was not significantly different from that in the placebo group, although it was significantly different from baseline $(p<0 \cdot 05)$.

Cholestyramine produced similar reductions in total plasma cholesterol concentration $(23 \%)$, low density lipoprotein cholesterol concentration $(31 \%)$, and ratio of low density lipoprotein cholesterol to high density lipoprotein cholesterol (34\%) to those observed with pravastatin. However, plasma triglyceride concentrations rose $(18 \%)$ on treatment with the resin $(\mathrm{p}<0.01)$.

The results observed at 12 weeks for lipid and lipoprotein parameters were maintained at 24 weeks. In the pravastatin treated group the mean reductions in total and low density lipoprotein cholesterol concentrations were $24 \%$ and $30 \%$ respectively. Plasma triglyceride concentration was reduced by $17 \%$. In the cholestyramine treated group the mean reductions in total and low density lipoprotein cholesterol values were $20 \%$ and $26 \%$ respectively. Plasma triglyceride concentration was increased by $6 \%$. The placebo groups assimilated at 12 weeks were not distinguishable at 24 weeks from the active treatment groups.

WITHDRAWALS AND ADVERSE EVENTS

No serious adverse drug reactions occurred during the study. Six patients were withdrawn because of symptoms, four on cholestyramine and one on placebo because of gastrointestinal symptoms and one from the pravastatin group for a rash which resolved after the drug was stopped. These patients were withdrawn within the 12 week placebo controlled treatment period.

No patient withdrew because of ocular problems or myositis-like symptoms. Three patients (one taking cholestyramine, one pravastatin, and one placebo) withdrew within the first 12 weeks for personal reasons (two due to job commitments, one unwilling to enter long term treatment). One further patient was withdrawn from the cholestyramine group because baseline lipid values were below the inclusion eligibility level.

\section{LABORATORY EVALUATIONS}

No patient was withdrawn from the study because of changes in liver function values. Transient increases in $\gamma$-glutamyltransferase activities ( $>1.5+$ baseline) were seen in three patients taking pravastatin and five on cholestyramine. However, activities of this enzyme rose above the upper limit of the normal range in only two patients, one on cholestyramine and one on pravastatin. This abnormality was observed at two time points in the cholestyramine treated patient and one time point in the pravastatin treated patient. Nine patients receiving pravastatin showed transient disturbances of other hepatic enzyme values, which were not associated with clinical symptoms and did not lead to withdrawal of the patients. In addition, similar changes in hepatic enzyme values were observed in three patients receiving cholestyramine and one receiving placebo. There were no significant alterations in haematological parameters. No patient showed persis- tently raised creatine kinase activities during the study. Transient increases $(>4 \times$ baseline) were observed in eight subjects - four on placebo, two on cholestyramine, and two on pravastatin

\section{Discussion}

The cellular cholesterol pool regulates the expression of cell membrane low density lipoprotein receptors which play a major part in controlling plasma low density lipoprotein cholesterol concentrations. When the cellular cholesterol pool is reduced low density lipoprotein receptor numbers increase which bind and take up low density lipoprotein cholesterol to maintain cellular cholesterol homoeostasis. ${ }^{10}$ The major regulatory step in cellular cholesterol synthesis is the conversion of 3-hydroxy-3-methylglutaryl coenzyme A to mevalonic acid, which is catalysed by the enzyme 3-hydroxy-3-methylglutaryl coenzyme A reductase. The discovery of naturally occurring inhibitors of 3-hydroxy-3-methylglutaryl coenzyme A reductase provided the opportunity for a physiological means of modifying cholesterol biosynthesis and the cellular cholesterol pool. ${ }^{18}{ }^{19}$ The introduction of these inhibitors into clinical practice represents a major advance in the pharmacological modification of low density lipoprotein cholesterol concentrations. ${ }^{1320.22}$

In this study we have compared the safety and efficacy of pravastatin, a new hydrophilic 3-hydroxy-3methylglutaryl coenzyme A reductase inhibitor, with cholestyramine. Pravastatin increases the expression of low density lipoprotein receptors in human liver. ${ }^{2}$ Cholestyramine is a basic anion exchange resin which remains unabsorbed after oral administration and binds to bile acids in the intestine, preventing their reabsorption. In response, more bile acid is produced in the liver from cholesterol, leading to increased expression of low density lipoprotein receptors." Hepatic cholesterol synthesis is also increased, which partially offsets the cholesterol lowering effect.

\section{PATIENT SELECTION}

The patients chosen for this study were heterozygous for familial hypercholesterolaemia and at high risk of premature coronary heart disease. These patients almost invariably require drug therapy in addition to nutritional counselling to reduce plasma low density lipoprotein cholesterol concentrations to near normal. ${ }^{25}$ At present there is no straightforward biochemical measure of low density lipoprotein receptor activity which will fully discriminate between heterozygotes for familial hypercholesterolaemia and normal people. Therefore, the familial hypercholesterolaemic subjects were identified on strict biochemical and clinical criteria, including the presence of tendon xanthomas to ensure as homogeneous a population as possible for study. This inevitably leads to bias in the selection of subjects, in that subjects without xanthomas (or without xanthomas in a first degree relative) were excluded. However, there is no evidence to suggest a differential response to treatment between xanthomatous and non-xanthomatous disease.

\section{DRUG EFFECTS}

In this study pravastatin and cholestyramine produced similar, substantial reductions in plasma cholesterol concentrations through the reduction of plasma low density lipoprotein cholesterol. The reduction of low density lipoprotein cholesterol of $30 \%$ with pravastatin was in line with results in a dose-response study in primary hypercholesterolaemia. ${ }^{26}$ The response to cholestyramine in this study was greater than some other studies would predict. ${ }^{27}{ }^{28}$ However, patients chosen for study were recruited on the basis that they were able to tolerate a full or near full dose of the resin. 
Nevertheless, cholestyramine was highly effective in lowering low density lipoprotein cholesterol concentrations in this study in resin tolerant patients. No consistent changes in values of high density lipoprotein cholesterol were observed with either pravastatin or cholestyramine. Plasma triglyceride concentrations showed the expected small increase with cholestyramine. ${ }^{28}$

Pravastatin was generally well tolerated and side effects were few. The principal problems with other available reductase inhibitors have been rises in hepatocellular enzyme activities (greater than threefold increase) in $1 \cdot 0-1 \cdot 5 \%$ of patients and a rare myositis-like syndrome with raised plasma activities of creatine kinase ( $>10$-fold increase) in $0.5 \%$ of subjects. ${ }^{29}$ These effects are generally reversible on cessation of treatment although rhabdomyolysis has rarely been described in patients receiving lovastatin combined with cyclosporin, nicotinic acid, and gemfibrozil. ${ }^{30-33}$ In this study no patient was withdrawn because of a myositislike syndrome or excessive rises in creatine kinase activities. No patients were withdrawn because of disturbances in hepatic enzymes.

Careful ophthalmological examination revealed no changes in ophthalmic status in any patient on either treatment. This is of importance as the compound triparanol, which was in trial in the 1960 s as an inhibitor of cholesterol synthesis, led to cataract formation. However, this compound inhibits cholesterol synthesis at a late stage in the synthetic pathway, leading to a build up of toxic intermediates. ${ }^{34}$ Cataract development has not been observed in animals given long term high dose pravastatin. Furthermore, the other available reductase inhibitors which can produce cataract formation in some high dose toxicology studies in animals have not resulted in ophthalmological problems in humans..$^{29336}$

\section{CONCLUSION}

In conclusion, pravastatin seems to be an effective, well tolerated compound for treating severe hypercholesterolaemia. Cholestyramine when tolerated at high dose is also highly effective. Evidence from other studies indicates that the combination of pravastatin with cholestyramine has a greater effect in reducing low density lipoprotein cholesterol values than either compound used alone. ${ }^{14}$ Moreover, with regard to compliance, particularly when the drug needs to be taken with cholestyramine, it is now recognised that once daily dosing in the evening is as effective as twice daily dosing at the same total daily dosage. ${ }^{14}$

1 Consensus Conference. Lowering blood cholesterol to prevent heart disease. 7AMA 1985;253:2080-6.

FAMA 1985;253:2080-6.
2 Study Group of the European Atherosclerosis Study. Strategies for the Study Group of the European Atherosclerosis Study. Strategies for the
prevention of coronary heart disease; a policy statement of the European prevention of coronary heart disease; a policy stach
Atherosclerosis Society. Eur Heart $f$ 1987;877:88.

3 Oliver MF, Heady JA, Morris JN, Cooper J, Geizerova H, Gyarfas I, et al. Atromid-S. A cooperative trial in the primary prevention of ischaemic heart disease using clofibrate: a report from the Committee of Principal Investigators. Br Heart f 1978;40:1069-118.

4 Lipid Research Clinics Program. The lipid research coronary primary prevention trial results I and II. FAMA 1984;251:351-74.

5 Frick $M H$, Elo $O$, Haapa $K$, Heinonen OP, Heinsalmi P, Helo P, et al. Helsinki heart study: primary prevention trial with gemfibrozil in middleaged men with dyslipidemia. N Engl f Med 1987;317:1234-45.

6 Blankenhorn DH, Nessim SA, Johnson RL, Sanmarco ME, Azen SP, CashinHemphill L. Beneficial effects of combined cholesterol-niacin therapy on coronary

7 Brown G, Albers JJ, Fisher LD, Schaefer SM, Lin J-T, Kaplan C, et al. Regression of coronary artery disease as a result of intensive lipid-lowering therapy in men with high levels of apolipoprotein B. N Engl f Med 1990;322:1289-98.

8 Kane JP, Malloy MJ, Ports TA, Phillips NR, Diehl JC, Havel RJ. Regression of coronary atherosclerosis during treatment of familial hypercholesof coronary atherosclerosis during treatment of familial hype
terolemia with combined drug regimens. $7 A M A$ 1990;264:3007-12.

9 Stanbury JB, Wyngaarden JB, Frederickson DS, Goldstein JL, Brown MS, eds. Familial hypercholesterolemia. In: The metabolic basis of inherited disease. 5th ed. New York: McGraw Hill, 1983:672-712.

10 Brown MS, Goldstein JL. A receptor-mediated pathway for cholesterol homeostasis. Science 1986;232:34-47.

11 Study Group of the European Atherosclerosis Society. The recognition and management of hyperlipidaemia in adults: a policy statement of the European Atherosclerosis Society. Eur Heart $\mathcal{F}$ 1988;9:571-600.

12 Tikkanen MJ, Nikkila EA. Current pharmacological treatment of elevated serum cholesterol. Circulation 1987;76:529-33.

13 Grundy SM. HMG-CoA reductase inhibitors for treatment of hypercholesterolemia. $N$ Engl f Med 1988;319:24-33.

14 La Rosa JC, ed. New advances in the control of lipid metabolism: focus on pravastatin. London: Royal Society of Medicine, 1989. (International congress and symposium series No 162.)

15 Expert Panel. Report of the National Cholesterol Education Program Expert Panel in the detection, evaluation and treatment of high blood cholesterol in Panel in the detection, evaluation and tre
adults. Arch Intern Med 1988;148:36-69.

16 Burstein M, Scholnick HR, Morfin R. Rapid method for the isolation of lipoproteins from human serum by precipitation with polyanions. f Lipid Res 1970;11:583-95.

17 Friedewald WT, Levy RI, Frederickson DS. Estimation of the concentration of low density lipoprotein cholesterol in plasma without use of the preparative ultracentrifuge. Clin Chem 1972;18:499-502.

18 Endo A, Juroda M, Tsujita Y. ML-236A, ML-236B and ML-236C, new inhibitors of cholesterogenesis produced by Penicillium citrinum. $\mathcal{F}$ Antibio (Tokyo) 1976;29:1346-8.

19 Alberts AW. Discovery, biochemistry and biology of lovastatin. Am $f$ Cardiol $1988 ; 62: 10-5 \mathrm{~J}$

20 Hoeg JM, Brewer HB. 3-Hydroxy-3-methylglutaryl coenzyme A reductase inhibitors in the treatment of hypercholesterolemia. fAMA 1987;2598: 3532-6.

21 Bradford RH, Shear CL, Chremos AN, Dujovne C, Downton M, Franklin FA, et al. Expanded clinical evaluation of lovastatin (EXCEL) study results. Arch Intern Med 1991;151:43-9.

22 Maher VMG, Thompson GR. HMG-CoA reductase inhibitors as lipidlowering agents: five years' experience with lovastatin and an appraisal of lowering agents: five years' experience with lovastatin
simvastatin and pravastatin. Qf Med 1990;74:165-75.

23 Reihner E, Rudling M, Stahlberg D, Berglund L, Ewerth S, Bjorkhem I, et al. Influence of pravastatin, a specific inhibitor of HMG CoA reductase on hepatic metabolism of cholesterol. $N$ Engl f Med 1990;323:224-8.

24 Rudling MJ, Reihner E, Einarsson K, Ewerth S, Angelin B. Low density lipoprotein receptor-binding activity in human tissues: quantitative importance of hepatic receptors and evidence for regulation of their expression in vivo. Proc Natl Acad Sci USA 1990;87:3469-73.

25 Goldstein JL, Brown MS. Familial hypercholesterolemia. In: Scriver CR, Beaudet AL, Sly WS, Valle D, eds. The metabolic basis of inherited disease. 6th ed. New York: McGraw-Hill, 1989:1215-50.

26 Hunninghake DB, Knopp RH, Schonfeld G, Goldberg AC, Brown WV, Schaefer EJ, et al. Efficacy and safety of pravastatin in patients with primary hypercholesterolaemia. Atherosclerosis. 1990;85:81-9.

27 Curtis LD, Dickson AC, Ling KLE, Betteridge DJ. Combination treatmen with cholestyramine and bezafibrate for heterozygous familial hypercholeswith cholestyramine and bezafibra

28 Brown MS, Goldstein JL. Drugs used in the treatment of hyperlipoproteinemias. In: Gilman AG, Goodman LS, Rall TW, Murad F, eds. Goodman and Gilman's the pharmacological basis of therapeutics. 7th ed. New York: Macmillan, 1985:827-45.

29 Tobert JA. Efficacy and long-term adverse effect pattern of lovastatin Am $\mathcal{F}$ Cardiol 1988;62:28-34J.

30 East C, Alivizatos OA, Grundy SM, Jones PH, Farmer JA. Rhabdomyolysis in patients receiving lovastatin after cardiac transplantation. $N$ Engl $\mathcal{f}$ Me 1988;3:47-8.

31 Corpier CL, Jones PH, Suke WN, Lederer ED, Quinones MA, Schmidt SW et al. Rhabdomyolysis and renal injury with lovastatin use. $\not A M A$ 1988;260:239-41

32 Reaven P, Witztum ML. Lovastatin, nicotinic acid and rhabdomyolysis. Ann Intern Med 1988;109:597-8.

33 Ayanian JZ, Fuchs CS, Stone RM. Lovastatin and rhabdomyolysis. Ann Intern Med 1988;109:682-3.

34 Laughlin RC, Carey TF. Cataracts in patients treated with triparanol. FAMA 1962;181:339-40.

35 Hunninghake DB. Lovastatin: followup-ophthalmic data. JAMA 1988;259. 354-5.

36 Tobert JA. New developments in lipid-lowering therapy: the role of inhibitors of hydroxymethyl glutaryl coenzyme A reductase. Circulation 1987;76: 534-8

(Accepted 18 March 1992) 